\title{
Differential Neutralization of Spontaneous and Centrifuge-assisted Chlamydial Infectivity
}

\author{
By S. AINSWORTH, I. ALLAN AND J. H. PEARCE \\ Department of Microbiology, University of Birmingham, Birmingham B15 2TT
}

(Received 12 February 1979)

\begin{abstract}
Neutralization by specific antibody of a fast-killing variant strain of Chlamydia trachomatis, which showed high spontaneous infectivity for cell monolayers, was examined. It appeared that in spontaneous infection antibody-treated chlamydiae were neutralized by inhibition of attachment to cells. Centrifugation imposed a different effect: infection was inhibited at some step at or subsequent to attachment.
\end{abstract}

\section{INTRODUCTION}

The capacity of antibody to neutralize chlamydial infectivity for cell cultures is well documented (Reeve \& Graham, 1962; Blyth et al., 1962; Graham \& Layton, 1971). Its relevance to immunity (Mogg et al., 1971) has been little examined, perhaps because neutralizing antibody is generally of low titre unless enhanced by antiglobulin treatment (Williams \& Hahon, 1970; Zakay-Rones \& Becker, 1971; Blyth \& Taverne, 1974).

Possible mechanisms of neutralization of chlamydiae have been suggested by later work. Abortive infection of cell cultures by antibody-treated chlamydiae may occur because the coated, ingested organisms cannot inhibit lysosomal fusion (Friis, 1972). Howard (1975) has demonstrated complement-mediated neutralization of Chlamydia trachomatis by serum antibody, to high titre, although whether the neutralization occurs extra- or intracellularly is unclear. The pioneering studies of Nichols and colleagues (Nichols et al., 1973) showed that incubation of strains of $C$. trachomatis with serum and eye secretion antibody could reduce conjunctival infection in owl monkeys. Although lacking experimental evidence, they drew attention to inhibition of attachment to cell and mucous surfaces as a further mechanism of neutralization.

In preliminary studies, we observed that chlamydiae treated with antibody and neutralized for spontaneous (static cell) infection of cell monolayers were still infective in centrifugeassisted infection. This differential effect was especially marked with the guinea-pig inclusion conjunctivitis strain (GP-IC) of C. psittaci (Allan et al., 1977); it appeared possible that neutralization of spontaneous infection resulted from prevention of attachment.

In the present work, we have studied a 'fast-killing' variant strain of $C$. trachomatis, chosen because of its intrinsically high spontaneous infectivity for monolayers (Wang \& Grayston, 1971). Evidence is presented that antibody treatment can lead to inhibition of attachment in spontaneous infection; neutralization of centrifuge-assisted infection is determined at some step at or subsequent to attachment. A preliminary account of this work has appeared (Ainsworth et al., 1976). 


\section{METHODS}

Organism. The fast egg-killing variant, MRC4f, of C. trachomatis, was grown in chick embryos, harvested and purified (Moore et al., 1974). Suspensions of organisms $(0.1 \mathrm{ml})$ were stored at $-70^{\circ} \mathrm{C}$ until use. The stock suspension contained $1.5 \times 10^{9}$ chlamydial particles $\mathrm{ml}^{-1}$, as measured by dark-ground microscopy (Reeve \& Taverne, 1962). For titration, suspensions were diluted in phosphate-buffered saline pH 7.2 (Dulbecco \& Vogt, 1954), containing $0.25 \mathrm{M}$-sucrose and $1 \%(\mathrm{v} / \mathrm{v})$ of a $7.5 \%(\mathrm{w} / \mathrm{v})$ solution of bovine serum albumin (fraction V; Grand Island Biological Co., New York, U.S.A.); this diluent, designated SPBSA, minimized thermal inactivation.

Antibody preparations. Immunoglobulin fractions of rabbit antiserum to MRC4f were a gift from Dr $\mathbf{J}$. Stephen, Department of Microbiology, University of Birmingham. Antiserum to MRC4f had been raised against organisms passaged once in HeLa cells (Sim \& Stephen, 1975).

Sheep antiserum to normal rabbit immunoglobulin, a gift from Dr D. Catty, Department of Immunology, University of Birmingham, was dialysed against phosphate-buffered saline to remove preservative before use.

Antiserum and globulin fractions were stored at $-20^{\circ} \mathrm{C}$; before use, the latter were diluted with 9 vol. SPBSA to give a globulin concentration equivalent to that in serum, and both serum and globulin preparations were heated at $56^{\circ} \mathrm{C}$ for $30 \mathrm{~min}$.

Cell cultures. McCoy cells were grown in Eagle's minimal essential medium containing $5 \%(\mathrm{v} / \mathrm{v})$ foetal bovine serum (growth medium), harvested, irradiated and monolayers were prepared as previously described (Griffiths et al., 1976); monolayers were used 24 to $96 \mathrm{~h}$ after irradiation of cells.

Infectivity titration. To measure spontaneous infection, replicate cell monolayers, from which growth medium had been removed, were inoculated with $0.2 \mathrm{ml}$ of diluted chlamydial suspensions and incubated for $90 \mathrm{~min}$ at $35^{\circ} \mathrm{C}$. For centrifuge-assisted infection, inoculated monolayers were centrifuged at $1580 \mathrm{~g}$ for $90 \mathrm{~min}$ at $35^{\circ} \mathrm{C}$ (Griffiths et al., 1976). Inoculum supernatants were then removed and replaced by fresh growth medium $(1 \mathrm{ml})$. The inoculated monolayers were incubated for $42 \mathrm{~h}$, fixed in methanol and stained; inclusions were counted in monolayers in triplicate (Griffiths et al., 1976).

Neutralization of infectivity by antibody. Chlamydial suspensions were quickly thawed $\left(37^{\circ} \mathrm{C}\right)$ and diluted, and $0.1 \mathrm{ml}$ portions were mixed with $0.1 \mathrm{ml}$ of either diluted globulin preparations or SPBSA. The mixtures were incubated for $15 \mathrm{~min}$ at $37^{\circ} \mathrm{C}$ and diluted approx. 1 in 1000 before titration for infectivity. In certain experiments, normal rabbit globulin in SPBSA was substituted for SPBSA alone, but was without effect; SPBSA was therefore regarded as a satisfactory control medium for all experiments in which the effect of antibody was examined.

In some experiments, organism-antibody mixtures, before dilution, were incubated with sheep antiserum to rabbit immunoglobulin for $15 \mathrm{~min}$ at $37^{\circ} \mathrm{C}$ (Blyth \& Taverne, 1974) and assayed for residual infectivity by centrifugation. An attempt was made to reverse neutralization in both organism-antibody and organismantibody-antiglobulin mixtures by ultrasonic treatment. Suspensions $(1 \mathrm{ml})$ were sonicated for $30 \mathrm{~s}$ periods, with $30 \mathrm{~s}$ intervals of chilling, for a total of 120 to $240 \mathrm{~s}$ (Rapidis 180, 75 W, $3 \mathrm{~mm}$ tip; Ultrasonics Ltd, Shipley, Yorks.). Control experiments demonstrated that incubation of organisms with antiglobulin or normal globulin did not affect centrifuge-assisted infectivity and that sonication did not inactivate chlamydiae. However, in SPBSA, thermal inactivation resulted in approximately $15 \%$ loss of infectivity (measured by centrifugation) during incubation for $1 \mathrm{~h}$ at $35^{\circ} \mathrm{C}$; the results presented have been corrected for this.

Measurement of the effect of antibody on the distribution of organisms between monolayers and supernatants in spontaneous infection. Organisms were incubated with antibody and the mixture was used to infect six replicate monolayers spontaneously as previously described. Supernatants were then removed, pooled and titrated for residual infectivity by centrifugation $(60 \mathrm{~min})$. Infectivity associated with monolayers, after rinsing with $0.2 \mathrm{ml}$ SPBSA, was measured by ultrasonic disruption of cells (30 s exposure of monolayer in $0.6 \mathrm{ml}$ SPBSA); the sonicate from three monolayers was combined and titrated for infectivity by centrifugation with fresh monolayers. In control experiments, organisms or organism-antibody mixtures added to monolayers showed no marked loss of infectivity after ultrasonic disruption.

In a further experiment, inocula were incubated with monolayers which had been fixed in $1.25 \%(\mathrm{v} / \mathrm{v})$ glutaraldehyde (grade 1, Sigma) in phosphate-buffered saline $\mathrm{pH} 7 \cdot 2$ for $1 \mathrm{~min}$ at $20^{\circ} \mathrm{C}$ and then rinsed six times in SPBSA; infectivity in supernatants and from monolayers disrupted ultrasonically was titrated by centrifugation with fresh monolayers.

Measurement of the effect of antibody on the distribution of organisms between monolayers and supernatants in centrifuge-assisted infections. Organisms were incubated with antibody and the mixture was inoculated on to four replicate monolayers. Supernatants from four monolayers were pooled and titrated by centrifugation with fresh monolayers before and after ultrasonic treatment $(120 \mathrm{~s})$. Infectivity in monolayers was measured by allowing organisms to develop inclusions within infected cells. 


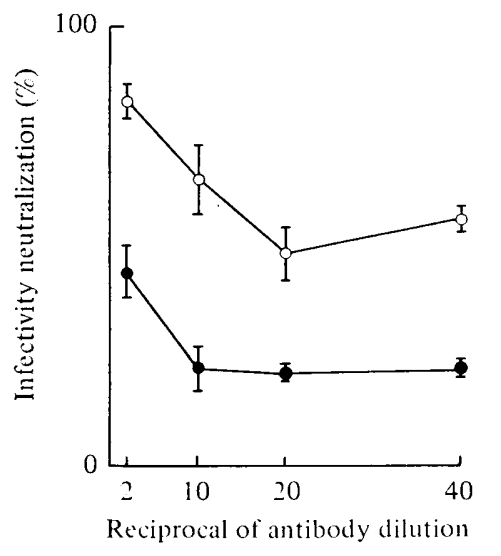

Fig. 1. Differential neutralization of MRC4f infectivity for cell cultures. Organisms (1 in 4 dilution of stock suspension) were incubated with antibody (dilutions of stock globulin preparation) for $15 \mathrm{~min}$ at $37^{\circ} \mathrm{C}$, diluted in SPBSA and titrated for spontaneous $(O)$ and centrifuge-assisted

(O) infectivity. Neutralization of infectivity by antibody is expressed as a percentage of the infectivity measured for organisms incubated in SPBSA alone and corrected for thermal inactivation. Values are means, \pm standard error, for three or more experiments.

\section{RESULTS}

\section{Differential neutralization of chlamydial infectivity}

The stock suspension of MRC4f had centrifuge-assisted and spontaneous infectivity titres of $1.5 \times 10^{8}$ to $4.4 \times 10^{8}$ inclusion-forming units (i.f.u.) $\mathrm{ml}^{-1}$ and $1.3 \times 10^{7}$ to $6.7 \times 10^{7}$ i.f.u. $\mathrm{ml}^{-1}$, respectively, with a centrifuge-assisted:spontaneous infectivity ratio of about $7: 1$.

Neutralization of infectivity by antibody was examined with relatively high organism concentrations ( 1 in 4 dilution of stock suspension) in order to relate conditions for infectivity neutralization on monolayers to those for blocking of attachment of organisms to tissue samples, where, for technical reasons, high inoculum concentrations are required (S. Ainsworth \& J. H. Pearce, unpublished work).

Neutralization of spontaneous infectivity was significantly greater $(P<0.01$, Student's $t$ test) than for centrifuge-assisted infectivity at all antibody dilutions (Fig. 1). Similar differences were obtained when 1 in 2, 1 in 8 and 1 in 16 dilutions of the stock suspension of organisms were compared. Generally, neutralization decreased with higher organism or lower antibody concentration, as observed by others (Zakay-Rones \& Becker, 1971). Approx. 95\% neutralization of spontaneous infectivity was observed for a 1 in 2 dilution of the stock suspension of organisms incubated with antibody at a globulin concentration equivalent to that in serum; neutralization was less than $10 \%$ for a 1 in 200 dilution of globulin.

Non-specific neutralization of spontaneous or centrifuge-assisted infection was not observed when organisms were incubated with normal globulin. Neutralization of both forms of infection was fully reversed when organism-antibody mixtures were sonicated (120 to $240 \mathrm{~s}$ ) before titration. Neutralization of antibody-treated organisms was enhanced by addition of sheep antiserum to rabbit globulin (Blyth \& Taverne, 1974); this neutralization was not reversed by ultrasonic treatment. Addition of sheep antiserum to rabbit globulin to organisms incubated with normal globulin did not result in neutralization; nor was the infectivity of organisms, alone, appreciably neutralized by sheep antiserum to rabbit globulin. 


\title{
Table 1. Distribution of infectivity in supernatants and monolayers after spontaneous infection by organisms or organism-antibody mixtures
}

\begin{abstract}
Organisms ( 1 in 4 dilution of stock suspension) after incubation with antibody (1 in 10 dilution of globulin preparation) were diluted, inoculated on to cell monolayers and incubated to allow spontaneous infection. The monolayers were either (i) incubated for development of infected cells or (ii) sonicated and the disrupted cell suspension was titrated for infectivity by centrifugation with fresh monolayers; supernatants were assayed similarly. Values are means, \pm standard error, from three experiments. In one experiment, inocula were incubated with glutaraldehyde-fixed monolayers; values are means for counts on three monolayers. Infectivity in supernatants, sonicates and monolayers is expressed as a percentage of the infectivity of the inoculum titrated by centrifugation, corrected for thermal inactivation and, for organism-antibody inocula, corrected for approx. $17 \%$ neutralization of the centrifuge-assisted infectivity titre.
\end{abstract}

Percentage of inoculum infectivity

\begin{tabular}{|c|c|c|c|c|}
\hline \multicolumn{3}{|c|}{ Live cells } & \multicolumn{2}{|c|}{ 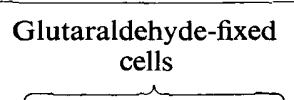 } \\
\hline Supernatant & $\begin{array}{l}\text { Monolayer } \\
\text { (developed } \\
\text { infection) }\end{array}$ & $\begin{array}{l}\text { Monolayer } \\
\text { (disrupted } \\
\text { cells) }\end{array}$ & $\begin{array}{l}\text { Super- } \\
\text { natant }\end{array}$ & $\begin{array}{l}\text { Monolayer } \\
\text { (disrupted } \\
\text { cells) }\end{array}$ \\
\hline $\begin{array}{l}75 \cdot 4 \pm 2 \cdot 4 \\
92 \cdot 6 \pm 7 \cdot 1\end{array}$ & $\begin{array}{r}13 \cdot 6 \pm 4 \cdot 2 \\
7 \cdot 4 \pm 1 \cdot 8\end{array}$ & $\begin{array}{r}10 \cdot 0 \pm 2 \cdot 1 \\
5 \cdot 0 \pm 1 \cdot 4\end{array}$ & $\begin{array}{l}66 \cdot 0 \\
82 \cdot 6\end{array}$ & $\begin{array}{r}13 \cdot 7 \\
8 \cdot 4\end{array}$ \\
\hline
\end{tabular}

\section{Effect of antibody on the distribution of organisms between supernatants and monolayers in spontaneous infection}

It appeared possible that neutralization of spontaneous infectivity resulted from inhibition of attachment of organisms to monolayers. This was investigated by the use of centrifugation to measure the level of infectivity in supernatants and associated with cells after incubation of inocula with static monolayers. The organism to antibody ratio was adjusted to give about $50 \%$ neutralization of spontaneous infectivity and under these conditions centrifuge-assisted infectivity was reduced by $17 \%$ (see Fig. 1).

Infection of monolayers was reduced from 13.6 to $7.4 \%$ by antibody treatment, with appreciably greater retention of infectivity in supernatants $(92.6 \%$ compared with $75.4 \%$, $P<0.05$; Table 1). The association of organisms with monolayers was reduced by antibody treatment, judged by titration of infectivity released from disrupted monolayers $(10 \%$ to $5 \%, P<0.05$; Table 1). Total recoveries of infectivity were lower for inocula of organisms than for organism-antibody inocula; this may have arisen from somewhat greater thermal inactivation on monolayers than that measured in incubated control suspensions (see Methods).

To confirm that monolayer-associated infectivity was not appreciably underestimated because of intracellular inactivation or release of organisms in the non-infective phase of their developmental cycle, the extent of attachment was examined with glutaraldehyde-fixed monolayers where no ingestion could take place. Attachment values were similar to those for live cells and, after antibody treatment, infectivity in supernatants was increased $(P<0.05)$ and attachment to monolayers decreased $(P<0.05)$.

\section{Effect of antibody on the distribution of organisms between supernatants and monolayers in centrifuge-assisted infection}

The above results demonstrate that antibody neutralized spontaneous infection by inhibition of attachment to cell monolayers. However, a proportion of organisms remained non-infective even after centrifugation (Fig. 1). To test whether this was also a result of failure of attachment, the distribution of antibody-treated organisms between supernatants and monolayers was examined after centrifuge-assisted infection. The organism to antibody ratio was selected to give maximum neutralization of spontaneous infection (approx. $45 \%$ 
Table 2. Distribution of infectivity in supernatants and monolayers after centrifuge-assisted infection by organisms or organism-antibody mixtures

Organisms ( 1 in 4 dilution of stock suspension) after incubation with antibody (1 in 2 dilution of globulin preparation) were diluted and centrifuged with monolayers. The monolayers were incubated for development of infected cells; supernatants and control samples of inocula were assayed, before and after sonication, by centrifugation with fresh monolayers. Infectivity in supernatants, monolayers and inocula is expressed as a percentage of the infectivity of the inoculum titrated by centrifugation and corrected for thermal inactivation. Values are means, \pm standard error, from five experiments.

\begin{tabular}{|c|c|c|c|c|}
\hline \multirow[b]{2}{*}{ Inoculum } & \multicolumn{4}{|c|}{ Percentage of inoculum infectivity } \\
\hline & Supernatant & $\begin{array}{l}\text { Supernatant } \\
\text { (sonicated) }\end{array}$ & $\begin{array}{l}\text { Monolayer } \\
\text { (developed } \\
\text { infection) }\end{array}$ & $\begin{array}{c}\text { Inoculum } \\
\text { (sonicated) }\end{array}$ \\
\hline $\begin{array}{l}\text { Organisms } \\
\text { Organism-antibody }\end{array}$ & $\begin{array}{l}4 \cdot 6 \pm 0.5 \\
9 \cdot 6 \pm 0.83\end{array}$ & $\begin{array}{c}\text { ND } \\
7 \cdot 4 \pm 2 \cdot 1\end{array}$ & $\begin{array}{l}95 \cdot 4 \pm 1 \cdot 0 \\
56 \cdot 0 \pm 3 \cdot 8\end{array}$ & $\begin{array}{l}93 \cdot 0 \pm 10 \cdot 6 \\
113 \cdot 0 \pm 1 \cdot 7\end{array}$ \\
\hline
\end{tabular}

mixture

ND, Not determined.

neutralization after centrifugation; Fig. 1). Infectivity in supernatants was measured after neutralization had been reversed by ultrasonic treatment $(120 \mathrm{~s})$. Of the inoculum incubated with antibody, $56 \%$ was infective after centrifugation with monolayers (Table 2). Although the infectivity of the supernatant was slightly higher than that for organisms alone $(9 \cdot 6$ versus $4.6 \%, P<0.01$; Table 2 ), $35 \%$ of the infectivity of the antibody-treated organisms was unaccounted for. The control suspension of organisms incubated with antibody showed full recovery of infectivity after ultrasonic treatment (Table 2) indicating that irreversible inactivation had not taken place during incubation. Since infectivity in supernatants was not increased by sonication, organisms rendered non-infective by antibody must have become associated with, and possibly ingested by, cells.

\section{DISCUSSION}

Recently Byrne (1978) clearly demonstrated that attachment and ingestion are discrete steps in endocytosis of chlamydiae, following earlier work by Friis (1972) which cast doubt on this question. Byrne \& Moulder (1978) also showed that antibody could inhibit attachment of radioactively labelled chlamydiae in infection of cells in suspension culture. Our results support this observation and emphasize the differing effect imposed by centrifugation on the fate of antibody-treated organisms. Neutralization in the latter case may have resulted from clumping of organisms which still firmly attach to cells, from failure of ingestion or possibly from inactivation through lysosomal discharge after entry into the cell (Friis, 1972; Lawn et al., 1973).

Centrifugation facilitates chlamydial infection, at least in part, by greatly increasing attachment; this may range from 5- to 7-fold, as with MRC4f, to more than 100-fold with other chlamydiae (Stirling \& Richmond, 1977; Griffiths et al., 1976). The facilitation occurs, not through sedimentation of organisms, but from induced cell surface changes (Allan \& Pearce, 1979), which may explain the failure of antibody to inhibit attachment in centrifugeassisted infection. This failure has the practical consequence that attachment-inhibiting antibody, of potential significance in infection, will be detected when chlamydial infectivity is titrated in spontaneous, but not centrifuge-assisted, infection. The effect may account for the observation that, for MRC4f infectivity, there was greater neutralization in spontaneous infection of monolayers by both homologous and heterologous antisera raised to other C. trachomatis strains than found for the latter when their infectivity was assayed by centrifugation (Graham \& Layton, 1971). 
Unlike MRC4f, substantial neutralization of the GP-IC strain of C. psittaci in spontaneous infection could be achieved without appreciable reduction in centrifuge-assisted infection (Allan et al., 1977). The effect may be determined by the specificity and concentration of antibodies in the respective antisera or by the different affinities of the two organisms for the cell surface, which may govern the extent of their spontaneous infection. MRC4f has a high capacity for spontaneous infection; GP-IC is typical of many other chlamydiae in only poorly infecting monolayers in the absence of centrifugation (spontaneous: centrifugeassisted infectivity ratio up to 1:3500; Griffiths et al., 1976). Hence, with GP-IC, binding of few antibody molecules could be sufficient to impair what may be an intrinsically weak association leading to spontaneous infection, without affecting centrifuge-assisted infection. In contrast, MRC4f particles may, on average, have to bind appreciably more antibody for spontaneous infection to be reduced so that a proportion undergoes substantial alteration and is also neutralized in centrifuge-assisted infection.

Attachment of MRC4f and its inhibition by antibody was similar for both live and glutaraldehyde-fixed cells. If specific cell receptors do determine attachment of fast-killing strains, as has been reported for trachoma strains (Kuo et al., 1973), then it would appear that their function was unimpaired by the fixation.

The significance of attachment inhibition in immunity to chlamydial infection is being investigated (Pearce et al., 1978).

This work was supported by a project grant from the Medical Research Council.

\section{REFERENCES}

Ainsworth, S., Allan, I. \& Pearce, J. H. (1976). Neutralisation and adherence of chlamydiae to mucous surfaces. Proceedings of the Society for General Microbiology 4, 14-15.

Allan, I. \& Pearce, J. H. (1979). Modulation by centrifugation of cell susceptibility to chlamydial infection. Journal of General Microbiology 111, 87-92.

Allan, I., Spragg, S. P. \& Pearce, J. H. (1977). Pressure and directional force components in centrifuge-assisted chlamydial infection of cell cultures. FEMS Microbiology Letters 2, 79-82.

Blyth, W. A. \& TAVERne, J. (1974). Neutralisation of TRIC organisms by antibody: enhancement by antisera prepared against immunoglobulins. Journal of Hygiene, Cambridge 72, 129-134.

Blyth, W. A., Reeve, P., Graham, D. M. \& TAVERNE, J. (1962). The production of antisera that neutralise inclusion blennorrhoea virus. British Journal of Experimental Pathology 43, 340343.

BYRNE, G. I. (1978). Kinetics of phagocytosis of Chlamydia psittaci by mouse fibroblasts ( $L$ cells): separation of the attachment and ingestion stages. Infection and Immunity 19, 607-612.

Byrne, G. I. \& Moulder, J. W. (1978). Parasitespecified phagocytosis of Chlamydia psittaci and Chlamydia trachomatis by $\mathbf{L}$ and HeLa cells. Infection and Immunity 19, 598-606.

Dulbecco, R. \& VogT, M. (1954). Plaque formation and isolation of pure lines with poliomyelitis virus. Journal of Experimental Medicine 99, 167-182.

FrIIS, R. R. (1972). Interaction of $\mathbf{L}$ cells and Chlamydia psittaci: entry of the parasite and host responses to its development. Journal of Bacteriology 110, 706-721.
Graham, D. M. \& Layton, J. E. (1971). The induction of chlamydia group antibody in rabbits inoculated with trachoma agents and demonstration of strain-specific neutralizing antibody in sera. In Trachoma and Related Disorders, pp. 145-157. Edited by R. L. Nichols. Amsterdam: Excerpta Medica.

Griffiths, M. S., Ainsworth, S. \& Pearce, J. H. (1976). Infectivity titration of guinea-pig inclusion conjunctivitis agent in irradiated McCoy cells. Journal of General Microbiology 95, 249-256.

HowARD, L. V. (1975). Neutralisation of Chlamydia trachomatis in cell culture. Infection and Immunity 11, 698-703.

Kuo, C. C., Wang, S. P. \& Grayston, J. T. (1973). Effect of polycations, polyanions and neuraminidase on the infectivity of trachoma-inclusion conjunctivitis and lymphogranuloma venereum organisms in HeLa cells: sialic acid residues as possible receptors for trachoma-inclusion conjunctivitis. Infection and Immunity 8, 74-79.

Lawn, A. M., Blyth, W. A. \& TaVerne, J. (1973). Interactions of TRIC agents with macrophages and BHK-21 cells observed by electron microscopy. Journal of Hygiene, Cambridge 71, 515-528.

Mogg, A. E., Collier, L. H. \& Harris, R. G. (1971). The antibody response to primary and repeated intravenous injections of TRIC agent. In Trachoma and Related Disorders, pp. 185-195. Edited by R. L. Nichols. Amsterdam: Excerpta Medica.

Moore, J. E., Griffiths, M. S. \& Pearce, J. H. (1974). Chlamydial infection of conjunctival tissues in culture. British Journal of Experimental Pathology 55, 396-405.

Nichols, R. L., Oertley, R. E., Fraser, C. E. O., 
Macdonald, A. B. \& McСомв, D. E. (1973). Immunity to chlamydial infections of the eye. VI. Homologous neutralisation of trachoma infectivity for the owl monkey conjunctivae by eye secretions from humans with trachoma. Journal of Infectious Diseases 127, 429-432.

Pearce, J. H., Ainsworth, S. \& Allan, I. (1978). Interaction of chlamydiae with host cell and mucous surfaces. Proceedings of the Society for General Microbiology 5, 81-82.

ReEVe, P. \& GrahaM, D. M. (1962). A neutralization test for trachoma and inclusion blennorrhoea viruses grown in HeLa cell cultures. Journal of General Microbiology 27, 177-180.

Reeve, P. \& Taverne, J. (1962). A simple method for total particle counts of trachoma and inclusion blennorrhoea viruses. Nature, London 195, 923-924.

Sim, I. S. \& STEPHEN, J. (1975). Studies on the purification of chlamydial agents grown in yolk sacs of embryonated eggs using disulphide-linked immunosorbents and enzymes. Journal of General Microbiology 89, 11-25.

Stirling, P. \& Richmond, S. (1977). The developmental cycle of Chlamydia trachomatis in McCoy cells treated with cytochalasin B. Journal of General Microbiology 100, 31-42.

Wang, S. P. \& Grayston, J. T. (1971). Studies on the identity of the 'fast' egg-killing chlamydia strains. In Trachoma and Related Disorders, pp. 322-336. Edited by R. L. Nichols. Amsterdam: Excerpta Medica.

Williams, T. D. \& Hahon, N. (1970). Serum neutralisation anti-IgG test for psittacosis. Infection and Immunity 2, 7-10.

ZAKAY-Rones, Z. \& BeckeR, Y. (1971). Antibodies to trachoma elementary bodies. In Trachoma and Related Disorders, pp. 254-259. Edited by R. L. Nichols. Amsterdam: Excerpta Medica. 